\title{
Regulation of the POU Domain Gene SCIP during Cerebral Cortical Development
}

\author{
Gretchen D. Frantz, Amy P. Bohner, Rebecca M. Akers, and Susan K. McConnell \\ Department of Biological Sciences, Stanford University, Stanford, California 94305
}

\begin{abstract}
The mammalian cerebral cortex is patterned into layers of neurons that share characteristic morphologies, physiological properties, and axonal connections. Neurons in the various layers are thought to acquire their lamina-specific identities shortly before the time of their final mitosis in the cortical ventricular zone. In order to investigate the molecular basis of laminar patterning in the CNS, we have performed in situ hybridization studies of the POU homeodomain gene SCIP (also known as Tst-1 or Oct-6), which is expressed in proliferating Schwann cells in the PNS and O2A progenitor cells in the developing CNS. In the CNS of adult rats, SCIP is expressed at high levels in the cerebral cortex, specifically in layer 5 pyramidal neurons that form subcortical axonal connections. SCIP is both temporally and spatially regulated during cortical development. Its initial expression in the intermediate zone and cortical plate is correlated with the early migration and differentiation of layer 5 neurons. SCIP hybridization was not, however, observed within the ventricular zone during the period of neurogenesis. SCIP is also expressed at high levels in the neurons of cortical layer 2/3, during their migration and differentiation within the cortical plate. This expression in the upper layers is apparently downregulated during postnatal periods, with the adult pattern apparent by postnatal day 30 (P30). POU domain genes are thought to play a role in cell lineage and cell fate decisions in several systems; thus, SCIP may serve a function in generating discrete laminar phenotypes in the developing cerebral cortex. In addition, since SCIP is a putative repressor of myelin gene expression, our results suggest that SCIP plays a role in regulating transcription in differentiated CNS neurons as well as in proliferating glial precursors.
\end{abstract}

[Key words: cerebral cortex, neurogenesis, homeodomain, migration, pattern formation, layers]

Homeodomain proteins have recently been implicated in the patterning of the mammalian CNS. Studies of the hindbrain (reviewed in Lumsden and Keynes, 1989; Lumsden, 1990; Wilkinson and Krumlauf, 1990), which is segmentally organized into rhombomeres during development, suggest that the rhom-

\footnotetext{
Received May 10, 1993; revised July 21, 1993; accepted July 26, 1993

We thank Ed Monuki and Greg Lemke for comments on the manuscript, for providing the SCIP clone and Schwann cell mRNA, and for many helpful discussions. We also thank Irina Burstein for help with plasmid preps and Northern blots, and Chris Kaznowski for technical assistance and help with photography. This work was supported by NIH EY06342 to G.D.F., and NIH EY08411, Pew Scholars, Searle Scholars, and a Clare Boothe Luce Professorship to S.K.M.

Correspondence should be addressed to Dr. Gretchen D. Frantz at the above address.

Copyright (c) 1994 Society for Neuroscience $0270-6474 / 94 / 140472-14 \$ 05.00 / 0$
}

bomeres are developmental compartments: they form domains of regulatory gene expression (Wilkinson et al.. 1989; Wilkinson and Krumlauf, 1990) across which there is little cell mixing (Fraser et al., 1990), and transplantation experiments show that rhombomeres retain their original positional identity in novel positions (Guthrie and Lumsden, 1991; Guthrie and Lumsden, 1992). Elsewhere in the CNS are a wide variety of regions showing nonsegmental patterns of neurons; these may be assembled during development using distinct mechanisms. Within the forebrain, the cerebral cortex is highly organizcd into layers and areas. Sections through the thickness of the cortex reveal that neurons form a series of layers, each defined by the density and morphology of its constituent cells. Neurons within a layer tend to share characteristic physiological properties and axonal connections that are typical of that layer (Gilbert and Kelly, 1975; Gilbert, 1977; Gilbert and Wiesel, 1985; LeVay et al., 1987). For example, in primary visual cortex, neurons in the superficial layers send long-distance axons to other cortical areas, whereas deep-layer cells generally project to subcortical targets (Gilbert and Kelly, 1975; Lund et al., 1975; Symonds and Rosenquist, 1984; McConnell and LeVay, 1986). In addition, the cortex is broken up tangentially into functionally distinct areas, each subserving a specific function such as analyzing incoming sensory information or coordinating motor outputs. Each area is characterized by distinctive cytoarchitectonic features (Brodmann, 1909), and the axonal connections of neurons in different areas reflect their functional specificity, such that (for example) visual cortical neurons receive information from and relay feedback to the visual nucleus of the thalamus, whereas somatosensory neurons are reciprocally connected with somatosensory thalamic regions (Kreig, 1946).

In contrast to the hindbrain, neocortical areas probably do not arise using compartmental mechanisms during development. Boundaries between cortical areas do not appear to be strictly determined at early ages, since cell mixing can occur between areas (O'Rourke et al., 1992; Walsh and Cepko, 1992; Fishell et al., 1993), and cortical areas have a broad developmental potential as assessed in transplantation experiments (Stanfield and O'Leary, 1985; O'Leary, 1989; O'Leary and Stanfield, 1989; Schlagger and O'Leary, 1991). No area-specific patterns of regulatory gene expression have yet been described (although it is certainly conceivable that such genes will be identified, and "nested" patterns of gene expression have been described in the cortex; Simeone et al., 1992a). Thus, one may (arguably) view the neocortex as one large developmental compartment within the forebrain; differences among cortical areas appear to emerge later in development through a series of epigenetic interactions (reviewed in (McConnell, 1992; Shatz, 1992). 
Nevertheless, the neocortex as a wholc appcars to be distinct from adjacent forebrain regions relatively early in development: it expresses several potential regulatory genes including Emx 1 and Emx2 (Simeone et al., 1992b), which are not expressed in the basal ganglia or piriform cortex. In a complementary manner, genes such as Dlx-1 and Dlx-2 are expressed in ventral forebrain including the developing basal ganglia, but not in neocortex (Porteus et al., 1991; Price et al., 1991, 1992). The apparent molecular boundary between neocortex and the developing striatum also appears to be a boundary that restricts cell movement: imaging studies of migrating ventricular cells show that cells that approach the ganglionic eminence (the striatal anlage) will not cross into this region (Fishell et al., 1993).

Although cortical areas may not be determined early in development, several lines of evidence suggest that the mechanisms of laminar patterning will involve early phenotypic commitments and molecular differences among layers (Shatz, 1992). First, transplantation studies show that the laminar identities of cortical neurons are determined early in development, during their final cell cycle just prior to mitosis (McConnell, 1988; McConnell and Kaznowski, 1991). Thus, committed premigratory cells are present within the cerebral ventricular zone. Second, migrating cortical neurons can "home" to the correct layer, actively recognizing their appropriate laminar address (McConnell, 1988; McConnell and Kaznowski, 1991). Furthermore, the intrinsic axons of cortical neurons innervate specific layers from the outset of their development (Katz, 1991), and neurons in cortical explants make lamina-specific choices of what are normally their long-distance targets in cocultures (Bolz et al., 1990; Yamamoto et al., 1992). Thus, the migration, axonal pathfinding, and target selection of neurons in the different layers are strikingly distinct from the earliest times studied, which implies that there are early molecular distinctions between layers.

A few studies have provided preliminary evidence for molecular correlates of laminar differences. In particular, Rosenfeld and colleagues have identified a family of POU homeodomain genes that are expressed in the mammalian CNS, a subset of which are expressed preferentially in the upper or deep layers of the cortex (He et al., 1989). POU genes are known transcriptional regulators that contain both a homeodomain and a POUspecific domain (Herr et al., 1988; Rosenfeld, 1991; Schöler, 1991), and have been directly implicated in cell fate decisions in the nematode worm Caenorhabditis elegans (Finney et al., 1988) and in the mammalian pituitary (Bodner et al., 1988; Ingraham et al., 1988; Li et al., 1990; Pfaffle et al., 1992). One of these genes, variously known as Tst-1 (He et al., 1989), SCIP (Monuki et al., 1989), or Oct-6 (Suzuki et al., 1990), was reported by $\mathrm{He}$ et al. (1989) to be expressed specifically in the deep cortical layers 5 and 6 in adulthood, and in the progenitors of these cells during development. SCIP is known to be expressed in glial cells in the PNS (Monuki et al., 1989, 1990) and CNS (Collarini et al., 1992). Evidence from studies of transfected cells in culture suggests that SCIP acts as a negative regulator of myelin gene expression (Monuki et al., 1990, 1993); thus, it has been hypothesized that SCIP is involved in the maintenance of Schwann cell proliferation (Monuki et al., 1989, 1990). The presence of SCIP/Tst-1 mRNA in the CNS (He et al., 1989), the suggestion that its expression may be layer specific, and the possibility that it might be expressed in mature neurons prompted us to characterize its spatial patterns of expression in the developing and adult cerebral cortex.

\begin{tabular}{lll}
\hline Table 1. Animals used for ${ }^{3}$ H-thymidine autoradiography \\
$\begin{array}{l}\text { Nay of }{ }^{3} \mathrm{H}- \\
\text { thymidine } \\
\text { injection }\end{array}$ & Day of perfusion & $\begin{array}{l}\text { Numimals } \\
\text { analyzed }\end{array}$ \\
\hline E14 & P2 & 1 \\
& Adult & 1 \\
E15 & Adult & 1 \\
E16 & E17 & 3 \\
& E20 & 2 \\
& P2 & 1 \\
& P10 & 1 \\
& P17 & 1 \\
E17 & Adult & 1 \\
E18 & Adult & 1 \\
& P2 & 1 \\
& P10 & 1 \\
& P17 & 1 \\
E19 & Adult & 1 \\
& P2 & 1 \\
& P10 & 1 \\
& P17 & 1 \\
& Adult & 1 \\
& & \\
& &
\end{tabular}

\section{Materials and Methods}

Animals. Timed-pregnant Long-Evans rats (Simonsen) were used for the developmental studies. The morning after breeding (the day a vaginal plug was detected) was considered embryonic day 0 (E0). A total of 10 pregnant females received injections of ${ }^{3} \mathrm{H}$-thymidine; of their offspring, 21 were included in the birthdating studies (Table 1). Three adult female rats were used for the Fluorogold retrograde tracing studies. A total of 29 developing and adult rats were used for in situ hybridization experiments, at the following ages: $\mathrm{E} 13(n=4$ rats), $\mathrm{E} 15(n=3)$, E16 $(n=2), \mathrm{E} 17(n=1), \mathrm{E} 18(n=1), \mathrm{E} 20(n=4), \mathrm{P} 2(n=1), \mathrm{P} 3(n=2)$, P6 $(n=1), \mathrm{P} 10(n=1), \mathrm{P} 14(n=2), \mathrm{P} 17(n=1), \mathrm{P} 21(n=1), \mathrm{P} 30(n$ $=1), \mathbf{P} 40(n=1)$, and adult $(n=3)$.

Preparation of RNA and Northern blots. Adult brains were dissected to separate cerebral cortical and hippocampal tissue, which were then frozen on dry ice. PolyA + mRNA was prepared from each tissue sample separately using Micro-Fast Track kits (Invitrogen). RNA was denatured on $1 \%$ agarose, $2.2 \mathrm{~m}$ formaldehyde gels, transferred to positively charged nylon membranes, and hybridized with random primed ${ }^{32} \mathrm{P}$-labeled probes (Sambrook et al., 1989) representing a 900 base pair region of the $3^{\prime}$ untranslated region of SCIP. Hybridization was carried out in $6 \times$ saline-sodium citrate (SSC) with $50 \%$ formamide, $0.5 \%$ SDS, $5 \times$ Denhardt's solution, and $0.2 \mathrm{mg} / \mathrm{ml}$ herring sperm DNA at $42^{\circ} \mathrm{C}$ for $36 \mathrm{hr}$, and high-stringency washes were done in $0.4 \times$ SSC with $0.5 \%$ SDS at $65^{\circ} \mathrm{C}$ for $30 \mathrm{~min}$.

${ }^{3}$ H-thymidine injections. Timed-pregnant rats received a single intraperitoneal injection of ${ }^{3} \mathrm{H}$-thymidine $(10 \mu \mathrm{Ci} / \mathrm{gm}$ body weight; New England Nuclear NET-027Z) on each of the following days: E14 (one rat), E15 (two rats), E16 (four rats), E17 (one rat), E18 (one rat), and E19 (one rat). One litter of fetuses injected with ${ }^{3} \mathrm{H}$-thymidine on E16 was fixed by immersion in $4 \%$ paraformaldehyde in $0.1 \mathrm{M}$ sodium phosphate buffer on E17, and a similar litter was fixed by immersion on E20. The remaining litters were allowed to deliver normally, and pups were perfused after a variety of survival times that are summarized in Table 1.

Perfusions and histology. Animals were anesthetized with an overdose of Nembutal ( $\geq 100 \mathrm{mg} / \mathrm{kg}$ body weight, i.p.). For in situ hybridization studies, whole embryos or brains were dissected out, immediately placed in OCT embedding compound, frozen on dry ice, and stored at $-70^{\circ} \mathrm{C}$ until use. Cryostat sections $(15 \mu \mathrm{m})$ were collected onto polylysinecoated slides, postfixed in $4 \%$ paraformaldehyde at $\mathrm{pH} 7.0$, rinsed in PBS, dehydrated, and stored at $-70^{\circ} \mathrm{C}$. For ${ }^{3} \mathrm{H}$-thymidine autoradiography, anesthetized animals were perfused transcardially with $0.1 \mathrm{M}$ sodium phosphate buffer followed by $4 \%$ paraformaldehyde in the same buffer. Brains were dissected out, sunk in fixative containing $20 \%$ su- 


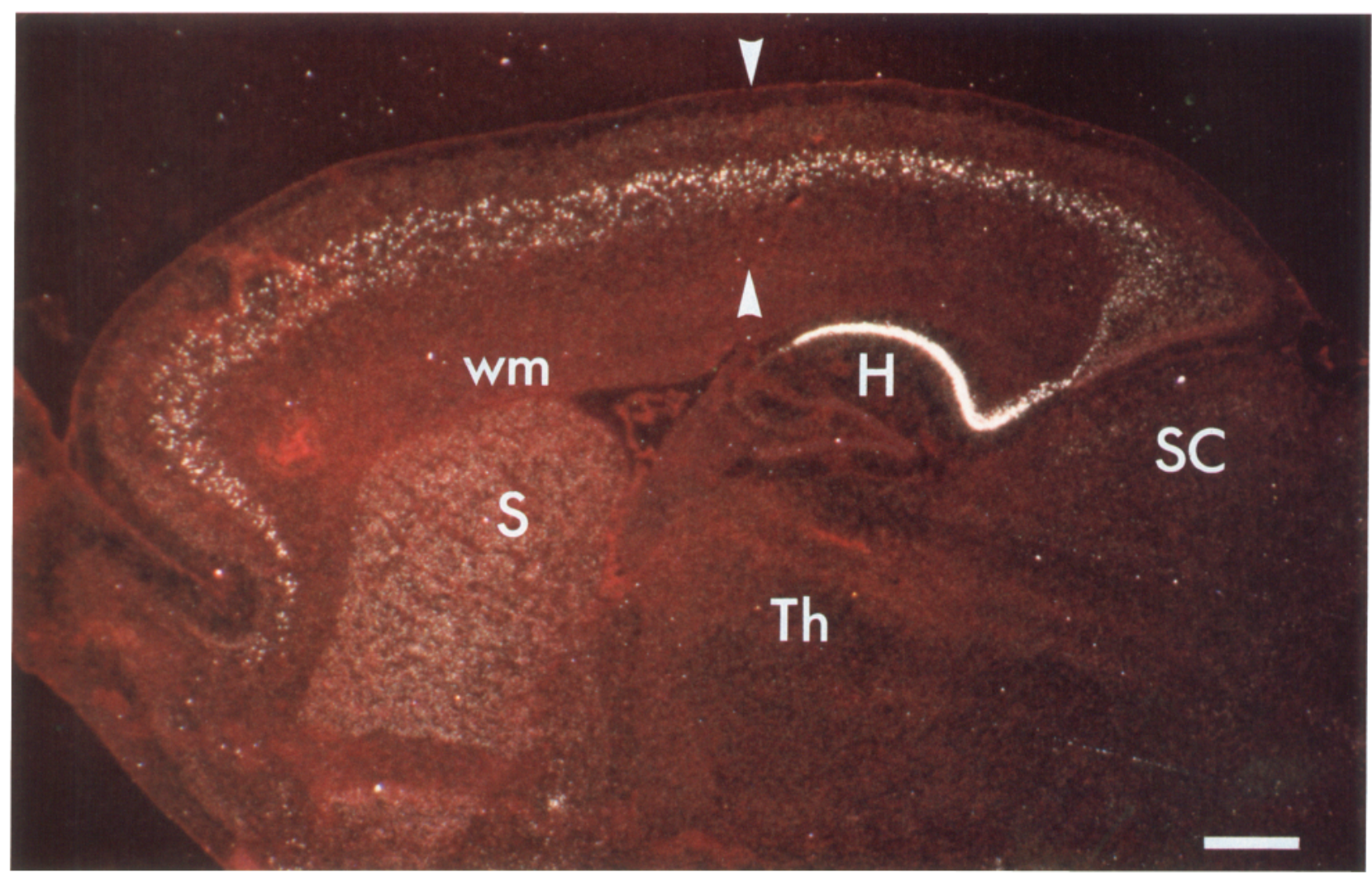

Figure 1. In situ hybridization for SCIP mRNA in the adult rat brain. This is a dark-field view of a parasagittal section counterstained with cresyl violet; anterior is to the left. Strong hybridization is present within the cerebral cortex (delineated by arrowheads), subiculum, CA1 region of the hippocampus $(H)$, striatum $(S)$, and superior colliculus $(S C)$, but is absent from most regions of the thalamus $(T h)$ and white matter $(w m)$. Scale bar, $1 \mathrm{~mm}$.

crose, and embedded in a mixture of gelatin and albumin. Sections were cut at $20 \mu \mathrm{m}$ on a freezing microtome, collected in fixative, mounted onto subbed slides, air dried, and dehydrated in a series of alcohols and xylenes. The sections were then dipped in $2 \%$ gelatin, dried, and then coated with Kodak NTB2 nuclear track emulsion. After 4-7 weeks in the dark at $4^{\circ} \mathrm{C}$, the sections were developed with Kodak D-19, fixed with Kodak Rapid Fix, and counterstained with cresyl violet. Cells that were heavily labeled with ${ }^{3} \mathrm{H}$-thymidine could be identified by the dense accumulation of silver grains overlying the cell nucleus. A labeled cell is defined as one that has at least half the maximal number of silver grains found over the most heavily labeled cells in that section; however, heavily labeled cells were readily distinguished from light-labeled and unlabeled cells by simple inspection. Quantitative analysis of the positions of ${ }^{3} \mathrm{H}$-thymidine-labeled neurons was performed by making camera lucida drawings of selected autoradiographs. The laminar positions of at least 300 heavily labeled neurons located in anterior occipital cortex of an adult animal were assessed for each age of injection.

In situ hybridization. SCIP sense and antisense riboprobes were transcribed from clone $046-2 \mathrm{~A}$ in pBluescript [representing 1.5 kilobases (kb) of the 3' untranslated region of the SCIP mRNA]. Linearization with $\mathrm{XbaI}$ and transcription with $\mathrm{T} 7$ polymerase produced antisense transcripts. Sense transcripts were synthesized from XhoI digested plasmid incubated with T3 polymerase. The in situ hybridization protocol was based on that of Simmons et al. (1989) with the modifications described below. Tissue pretreatments consisted of proteinase $\mathrm{K}$ digestions $(3.7 \mu \mathrm{g} / \mathrm{ml})$, followed by acetylation. Following overnight hybridization at $60^{\circ} \mathrm{C}$, sections were treated with ribonuclease $A(5 \mu \mathrm{g} / \mathrm{ml})$ at $37^{\circ} \mathrm{C}$. Sections were then treated with a high-stringency wash in $0.1 \times$ $\mathrm{SSC}$ at $60^{\circ} \mathrm{C}$. Slides were processed for autoradiography as above (but were not dipped in gelatin), and were exposed for 3 weeks before developing. Sense control probes revealed no hybridization above background (not shown).

Fluorogold retrograde tracing studies. Rats were deeply anesthetized with Nembutal $(55 \mathrm{mg} / \mathrm{kg}$, i.p.) and atropine $(0.04 \mathrm{mg} / \mathrm{kg}$, s.c.) and placed in a stereotaxic apparatus. To visualize callosally projecting neu- rons, four to eight injections of Fluorogold (5-7\% in saline, $0.4-0.7 \mu \mathrm{l} /$ injection) were made into medial and/or lateral regions of the contralateral cortex, at depths of $1.5-2.0 \mathrm{~mm}$ from the cortical surface. To label retrogradely subcortically projecting layer 5 neurons, seven injections of Fluorogold solution $(0.4 \mu \mathrm{l}$ each) were made at $1 \mathrm{~mm}$ intervals along a single puncture track extending from the superior colliculus to the pons. Animals were perfused with $4 \%$ paraformaldehyde at $\mathrm{pH} 9.5$, or with the same fixative at $\mathrm{pH} 6.5$ followed by fixative at $\mathrm{pH} 9.5$, after a 6-14 d survival period. The brains were removed and stored either overnight at $4^{\circ} \mathrm{C}$ in $4 \%$ paraformaldehyde containing $10 \%$ sucrose, or for $2 \mathrm{hr}$ at $4^{\circ} \mathrm{C}$ in PBS with $10 \%$ sucrose. Brains were sectioned on a cryostat at $20 \mu \mathrm{m}$, mounted on polylysine-coated slides, and desiccated in a vacuum overnight. Sections were then processed for in situ hybridization using methods similar to those described by Cunningham et al. (1991). Tissue pretreatments consisted of incubation in $1 \mu \mathrm{g} / \mathrm{ml}$ proteinase $\mathrm{K}$ for $30 \mathrm{~min}$, followed by two washes in $2 \times$ SSC and dehydration. Overnight hybridizations at $60^{\circ} \mathrm{C}$ were followed by $30 \mathrm{~min}$ incubations in $2.5 \mu \mathrm{g} / \mathrm{ml}$ of ribonuclease $\mathrm{A}(2.5 \mu \mathrm{g} / \mathrm{ml})$ at $37^{\circ} \mathrm{C}$. Highstringency washes in $0.1 \times$ SSC were performed for $30 \mathrm{~min}$ at 50 or $60^{\circ} \mathrm{C}$; none of the washes contained dithiothreitol in order to minimize loss of the Fluorogold label. To determine the fraction of Fluorogoldlabeled cells that were also positive for SCIP expression, we first located regions of the cortex in which a clean SCIP hybridization signal could be distinguished. Next all Fluorogold-labeled neurons in that region were identified and counted, and finally each cell was observed both with fluorescent illumination and in bright-field to determine whether individual cells were double labeled.

Photography and imaging. Selected sections were photographed using a Nikon UFX camera system for low-power color photomicrographs. For black and white figures, images were captured through an MTI CCD camera and processed on a Macintosh Quadra computer using Adobe PHOTOSHOP. Images showing SCIP expression within the developing cerebral wall (see Figs. 6-8) or adult cortex (Fig. 3) were taken from sagittal sections in regions overlying the hippocampus, typically representing anterior occipital cortex. 


\section{Results}

In the PNS, SCIP is expressed in proliferating Schwann cells and may act to regulate the expression of myelin genes such as $\mathrm{P}_{0}$ (Monuki et al., 1989, 1990; He et al., 1991). We were therefore curious to know first whether SCIP expression in the CNS is glial in origin (Collarini et al., 1992) or whether neurons express SCIP. Second, we wondered whether the patterns of SCIP expression might suggest a role for this gene in patterning the layers of the cerebral cortex (He et al., 1989).

\section{SCIP expression in adult cerebral cortex}

The pattern of SCIP expression was first characterized by in situ hybridization using a probe to the $3^{\prime}$ untranslated region of SCIP on adult rat brain. Figure 1 reveals that the SCIP probe hybridizes to a variety of brain regions, including the cerebral cortex, the CAl area of the hippocampus, subiculum, and striatum, and, in sections not pictured, also to the tenia tecta and indusium griseum. In general, the distribution of SCIP-expressing cells in this study matches closely that described for the POU gene Tst-1 (see Table 1 in He et al., 1989), which is identical to SCIP (He et al., 1989; Monuki et al., 1989; Rosenfeld, 1991; Schöler, 1991). We did not, however, observe SCIP expression in granule cells of the cerebellum either in adulthood or during development, as was reported by He et al. (1989).

Within the cerebral cortex, cells that express SCIP at high levels form a discrete band that corresponds to cortical layer 5 (Fig. 2). No hybridization above background is observed over cells of cortical layer 6 . This stands in contrast to the findings of He et al. (1989), who reported a significant level of Tst-1 expression over layer 6 as well as layer 5 . We also observed a low level of SCIP expression in layers 2 and 3, albeit much reduced compared to layer 5 : the labeling over single cell bodies, as assessed by counting the number of silver grains over each cell, is roughly sixfold higher in layer 5 than layer 2/3 (Fig. 3).

Layer 5 cells that express SCIP have very large, pale nuclei that resemble those of large pyramidal neurons (Fig. $3 B$ ). To ascertain directly whether SCIP-expressing cells are indeed neurons, and whether they form a single class of axonal projections, we retrogradely labeled layer 5 neurons from their long-distance axonal targets. Layer 5 neurons fall into two general categories, based on their projection patterns: the first, composed of large pyramids that tend to occupy the upper two-thirds of layer 5, send axons to subcortical targets that include the pons, superior colliculus, and spinal cord; the second, which tend to be somewhat smaller in size, are intracortical projection neurons that send axons to local cortical targets and across the corpus callosum (Koester and O'Leary, 1992). To establish whether cells that express SCIP extend an axon to subcortical or cortical targets, we injected the retrograde tracer Fluorogold into either subcortical (midbrain and brainstem) structures or into the contralateral cortical hemisphere. Midbrain/brainstem injections included the pons, descending pyramidal tract, and superior colliculus. Layer 5 neurons were retrogradely labeled following both types of injections, and contralateral cortical injections resulted in the labeling of neurons in layers besides layer 5 , as expected. Fluorogold-labeled sections were then processed for in situ hybridization, and the fraction of Fluorogold-labeled neurons within layer 5 that showed hybridization with the SCIP probe was determined. When layer 5 neurons were retrogradely labeled from subcortical injections, $64.4 \%$ of Fluorogold-labeled cells $(n=317)$ also expressed SCIP at high levels (Fig. 4). This

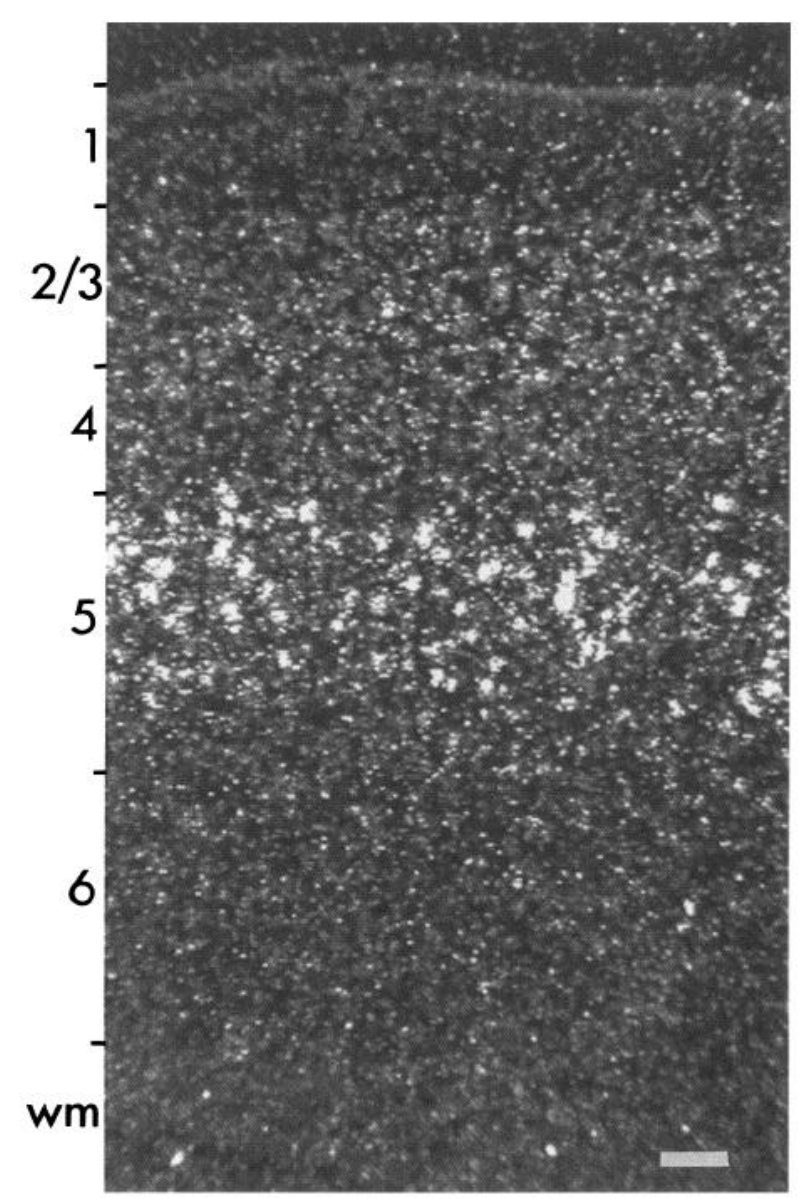

Figure 2. In situ hybridization for SCIP mRNA in the adult rat cerebral cortex. SCIP is expressed at high levels within cortical layer 5 , and at levels above background in layer $2 / 3$. $w m$, white matter. Scale bar, 100 $\mu \mathrm{m}$.

result shows definitively that SCIP-expressing cells in the cortex are indeed neurons. We then examined whether SCIP-expressing neurons form a distinct subset of layer 5 cells by assessing the fraction of callosal projection neurons in layer 5 that express SCIP. Within posterior (sensory) regions of cortex, which we define here as locations caudal to bregma (Paxinos and Watson, 1986), extremely few Fluorogold-labeled neurons showed hybridization. Only $4.7 \%$ of layer 5 neurons that were retrogradely labeled from the contralateral cerebral cortex $(n=361)$ hybridized with the SCIP probe. These results suggest that SCIP is expressed preferentially in those neurons within layer 5 that form a subcortical but not a callosal axonal projection. However, in very anterior cortical regions (rostral to bregma) corresponding to the frontal cortex, differences in SCIP expression between the two projection types were not so marked: here $32.9 \%$ of callosally projecting layer 5 cells $(n=89)$ expressed SCIP. In these anterior regions, most of the double-labeled callosal neurons were located within the bottom half of layer 5 .

No SCIP hybridization was observed over the small, dense nuclei of glial cells in the adult cerebral cortex (Fig. 3), nor was SCIP expressed in white matter regions that are composed predominantly of oligodendrocytes and fibrous astroglia (Fig. 1). Thus, in contrast to the glial expression of SCIP in proliferating cells in culture (Monuki et al., 1989, 1990; Collarini et al., 1992), SCIP is expressed by differentiated neurons in the adult cerebral cortex. Furthermore, the hybridization we observed was asso- 

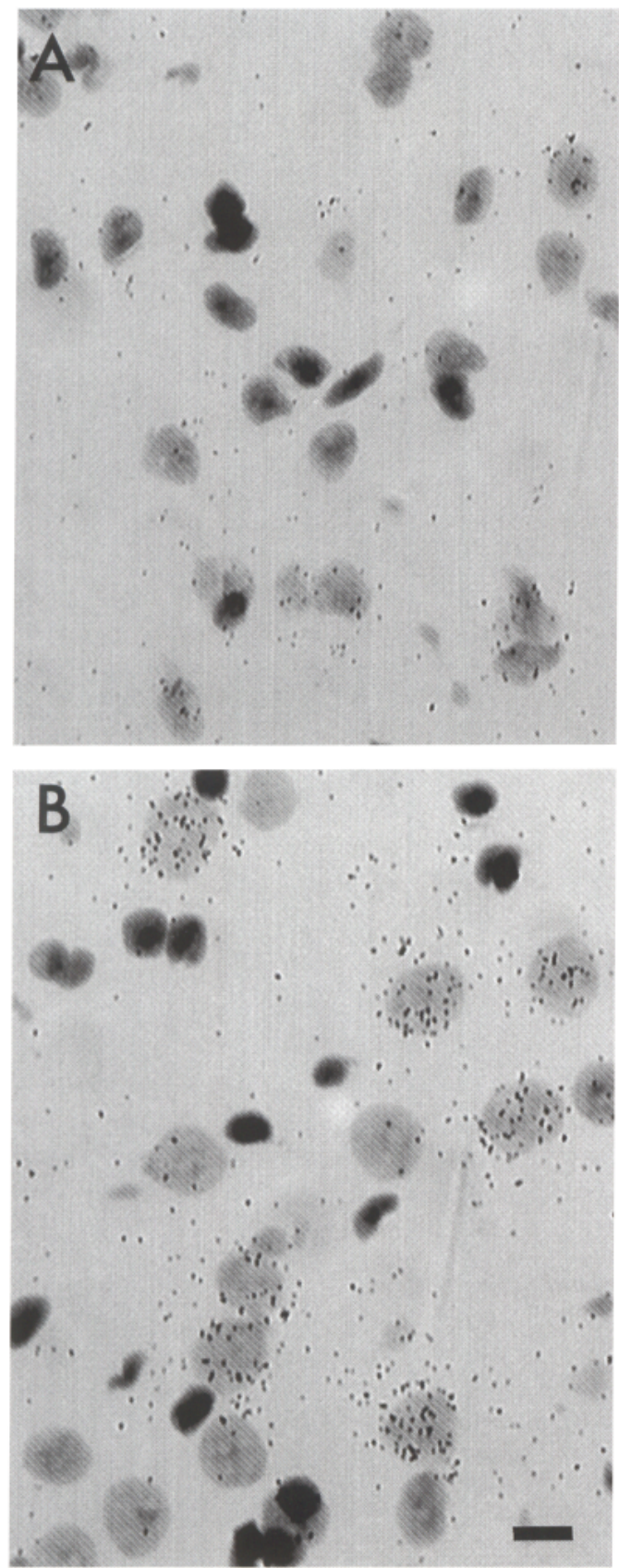

Figure 3. High-power view using bright-field optics of SCIP hybridization in cortical layer $2 / 3(A)$ and layer $5(B)$. In both cases, SCIP hybridization is apparent over large, pale neuronal nuclei, but is not present above background over the small, dense nuclei of glial cells. Levels of SCIP expression, as assessed by counting the number of silver grains over each cell, are roughly sixfold higher in layer 5 (on average, 60 grains/cell) than in layer $2 / 3$ (average of 10 grains/cell). Scale bar, $10 \mu \mathrm{m}$.

ciated with distinct cell types, particularly (but not exclusively) with the large subcortical projection neurons of cortical layer 5.

\section{Birthdates of neurons in the developing cortical layers}

In order to compare patterns of SCIP expression with the birth and migration of cells that express SCIP in adulthood, the times at which neurons in the different layers are generated were determined by injecting pregnant rats with ${ }^{3} \mathrm{H}$-thymidine. This technique marks the birthdays of neurons generated on specific
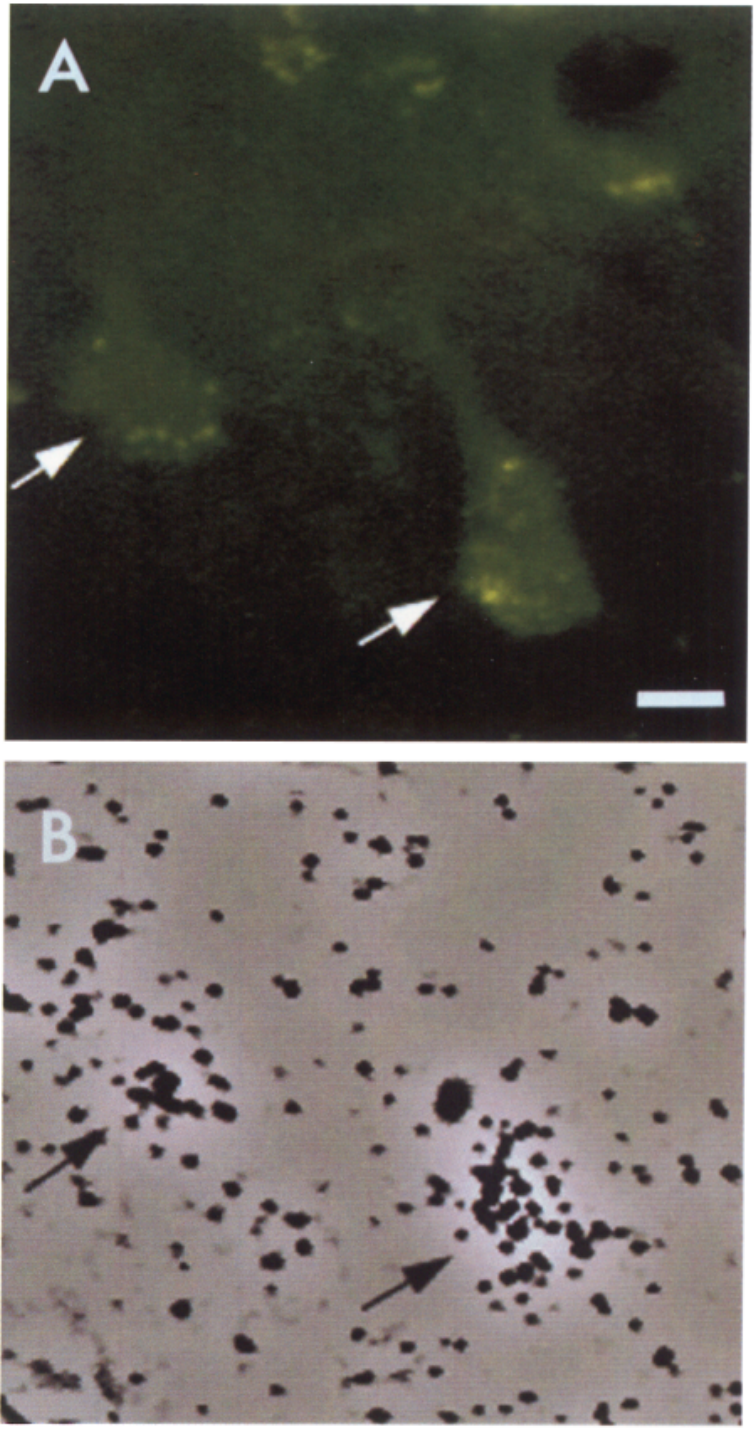

Figure 4. Combined retrograde labeling with Fluorogold and in situ hybridization for SCIP mRNA. A, Epifluorescence illumination reveals two neurons in cortical layer 5 (arrows) that were retrogradely labeled with Fluorogold following injections of this tracer into midbrain regions, including the pons and superior colliculus (see Materials and Methods). $B$, Most retrogradely labeled neurons also express SCIP at high levels: bright-field illumination of the same two neurons (arrows) reveals strong SCIP hybridization over their cell bodies. In total, about $65 \%$ of subcortically projecting neurons retrogradely labeled with Fluorogold also showed SCIP hybridization. Scale bar, $10 \mu \mathrm{m}$.

days in development. The results, summarized in Figure 5, are similar to those obtained in other thymidine birthdating studies of rat neocortex (Berry and Rogers, 1965; Hicks and D'Amato, 1968; Miller, 1985) and reveal the well-known inside-first, outside-last gradient of neurogenesis found in the cerebral cortex of all mammals that have been studied (Angevine and Sidman, 1961; Berry and Rogers, 1965; Rakic, 1974; Luskin and Shatz, 1985a). Layer 5 neurons, which express SCIP at high levels in adulthood, begin to be generated in significant numbers on around E15 and reach a peak at E16 (Fig. 5). Neurons of layer 2/3, which also express SCIP but at much lower levels in adult animals, are generated primarily on E18 and E19. The histograms shown in Figure 5 were obtained from regions of anterior occipital cortex, immediately overlying the hippocampus. Because 
E14

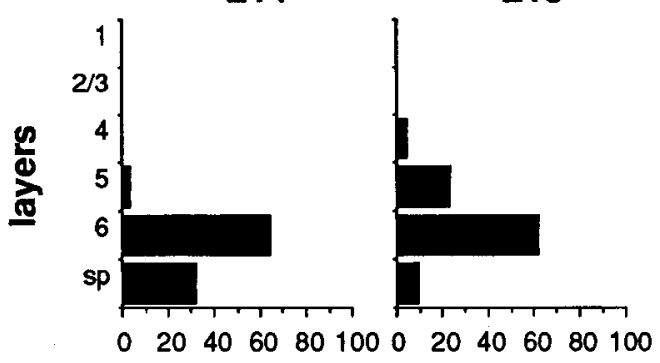

E16

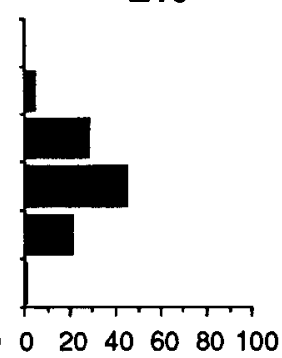

E17

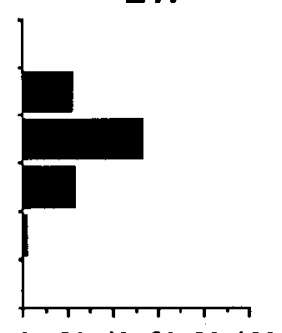

E18

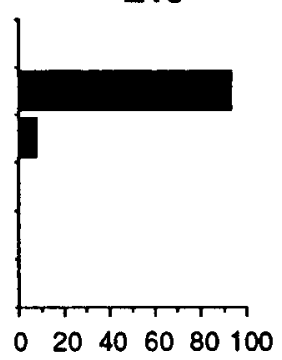

E19

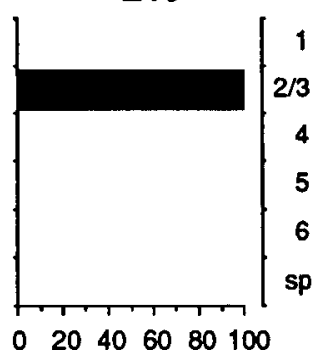

\section{$\%$ of $3 \mathrm{H}$-thymidine labeled cells}

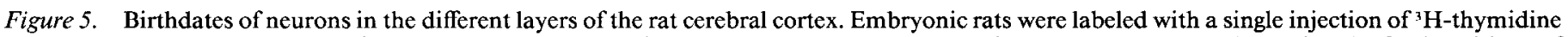

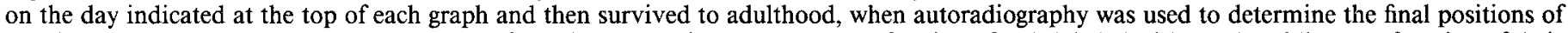

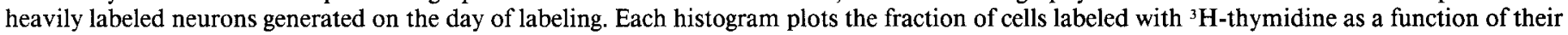

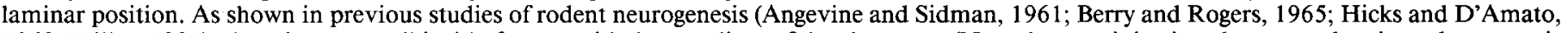

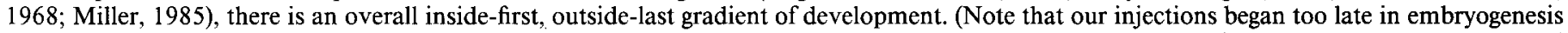

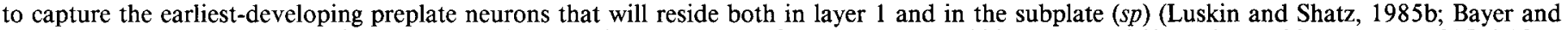

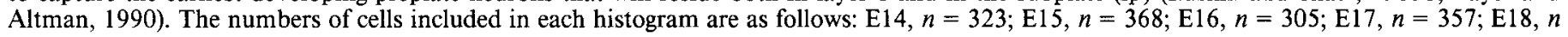
$=517$; $19, n=353$.

of the known rostrocaudal and mediolateral gradients of cortical histogenesis, regions rostral and lateral to this site exhibit slightly more advanced development, whereas the converse holds true in more caudal and medial cortical regions.

\section{Regulation of SCIP expression during cerebral cortical development}

The developing cerebral cortex was examined by in situ hybridization to assess the temporal and spatial patterns of SCIP expression at a variety of ages, beginning at E13. We then correlated these dynamic patterns with the birth and subsequent development of specific cortical layers, as revealed by experiments in which these neurons have been tagged on their birthday with ${ }^{3} \mathrm{H}$-thymidine. The in situ hybridization studies reveal a pattern of SCIP expression that is correlated with the birth, migration, and subsequent differentiation of neurons of cortical layers 5 and $2 / 3$.

E13. At E13, SCIP hybridization is associated with the preplate of the anteriormost portion of the cerebral wall (Fig. $6 A, B$ ). Within presumptive sensory regions of cortex, no SCIP expression is observed, and there is no detectable expression in the ventricular zone at any location. In the developing striatum, SCIP expression is localized to the subventricular zone of the ganglionic eminence, but is not associated with the ventricular layer of this region. SCIP is clearly detectable in the olfactory bulb and spinal cord as well (not shown).

E15. The pattern of SCIP expression at E1 5 is similar to that at E13, and hybridization is particularly obvious in the anterior preplate, olfactory bulh, and the subventricular zone of the ganglionic eminence (Fig. 6C,D). The preplate of more caudal sensory cortex also shows hybridization. Note the absence of SCIP expression in the ventricular zone, even though at this age many of the first neurons of cortical layer 5 are being generated (Fig. 5).

E16. At E16 SCIP hybridization is observed in the subventricular zone and intermediate zone of the cerebral wall, albeit at low levels (Fig. 7A). This pattern is apparent throughout the rostrocaudal extent of cortex. There is no detectable expression in the cortical plate or in the ventricular zone. The latter is of particular note since E16 represents the peak period of genesis of layer 5 neurons. The expression of SCIP in the intermediate zone at E16 appears to correlate with the migration of the first layer 5 neurons, born on E14-E15 (Fig. 5), out into the intermediate zone toward the cortical plate. Thus, the onset of SCIP expression within the lower part of the cerebral wall is correlated temporally and spatially with the migration of layer 5 neurons, but not with their genesis.

E17. The levels of SCIP expression are now quite strong in the subventricular and intermediate zones of E17 fetuses, but the cortical plate shows very little hybridization (Figs. $6 E, F$; $7 B$ ). Comparison of SCIP hybridization in the E1 7 intermediate zone (Fig. $7 B$ ) with the migration of thymidine-labeled neurons generated on E16 (Fig. $7 C$ ) shows a close spatial match: the area of SCIP expression corresponds closely to the area in which thymidine-labeled cells, the majority of which are destined for layer 5, are migrating within the intermediate zone. Note again in Figures $6 F$ and $7 B$ the absence of SCIP expression in the ventricular zone at the base of the cerebral wall.

$E 18$. The subventricular and intermediate zones continue to show high levels of SCIP expression (Fig. $6 G, H$ ). By E18, cells in the outer half of the cortical plate also express SCIP, while those cells in the deeper half of the cortical plate do not show hybridization above background levels. We believe that the unlabeled, lower half of the cortical plate corresponds to cortical layer 6 . On E18, the onset of upper-layer neurogenesis has begun (Fig. 5), yet the cortical ventricular zone shows no detectable SCIP expression.

E20. On E20, SCIP expression in the subventricular zone has weakened, hut a clear hand of SCIP-expressing cells is visible in the intermediate zone (Figs. $6 I, J ; 7 D$ ). A band of cells within the cortical plate express SCIP at high levels, but again there is little or no expression in the lower half of the cortical plate. Comparison of the pattern of SCIP expression with the positions of thymidine-labeled neurons reveals that cells tagged with ${ }^{3} \mathrm{H}$ thymidine on E16 (most of which are layer 5 neurons) have reached the cortical plate where they occupy its upper half (Fig. $7 E$ ). Their position overlaps precisely with the region of abundant SCIP hybridization (Fig. 7D). The band of SCIP signal in the intermediate zone probably correlates with the migrating wave of upper-layer neurons, first generated on E18, which take 

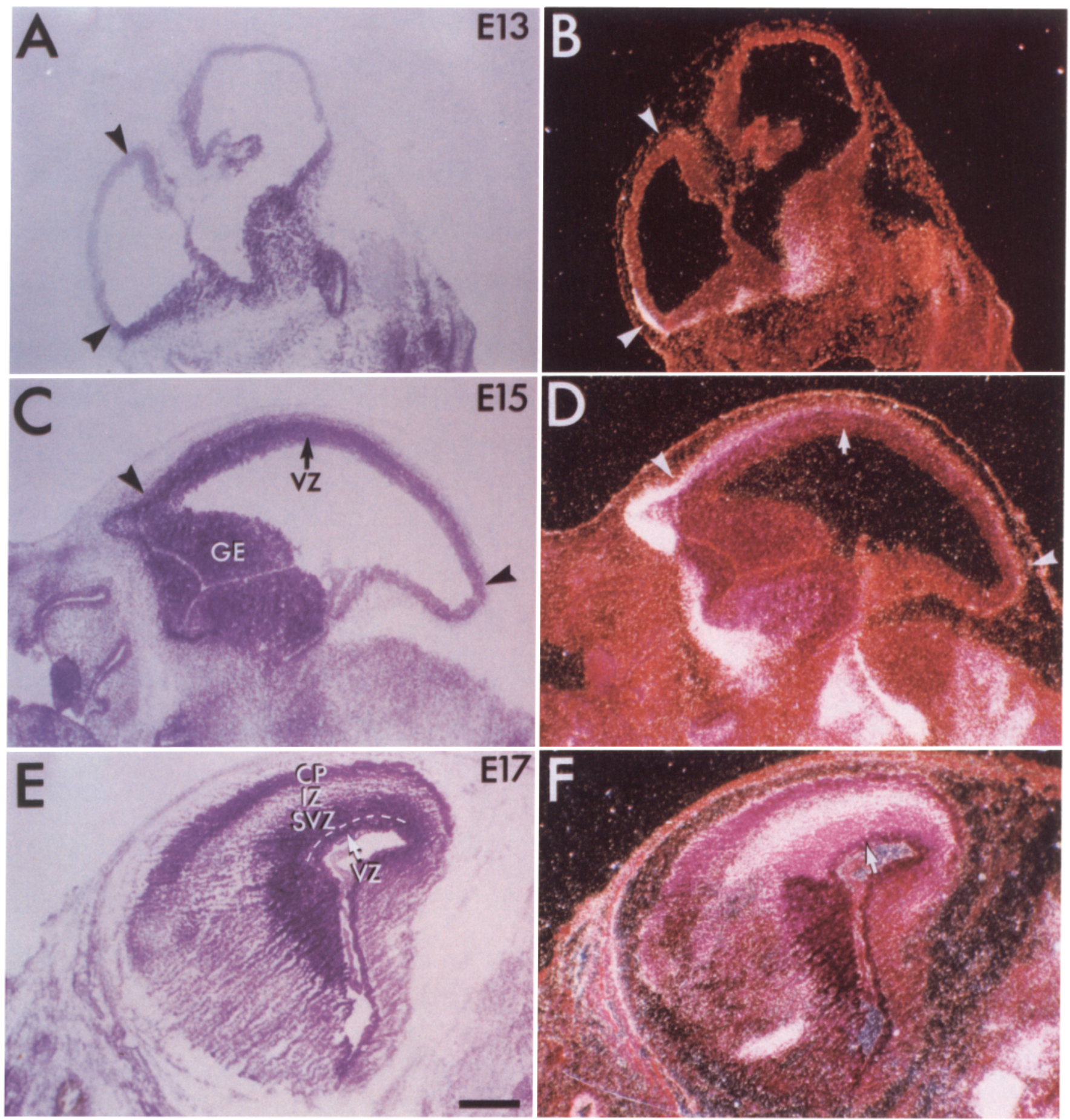

Figure 6. Developmental regulation of SCIP expression within the rat forebrain. $A, C, E, G, I$, and $K$, Bright-field view of sections counterstained with cresyl violet; parasagittal sections, anterior is to the left (except in $A$ and $B$, in which anterior is down). $B, D, F, H, J$, and $L$, Dark-field view of SCIP hybridization in the same or adjacent section to that shown on the left. $V Z$, ventricular zone; $S V Z$, subventricular zone; $I Z$, intermediate zone; $C P$, cortical plate. $A$ and $B, \mathrm{E} 13$ : SCIP is expressed in the preplate of the anteriormost region of cerebral cortex. The anterior-posterior extent of the cortex is marked by arrowheads. Hybridization is also present in the subventricular zone of the ganglionic eminence (the anlage of the striatum), and in the olfactory bulb and spinal cord (not shown). $C$ and $D$, E15: SCIP hybridization is apparent within the preplate of the cerebral wall (demarcated by arrowheads), within the olfactory bulb (to the left of the leftmost arrowhead), and within the subventricular zone of the ventral lobe of the ganglionic eminence $(G E)$. There is no detectable SCIP expression within the cerebral ventricular zone (arrow). $E$ and $F$, E17: Within

roughly $4-5 \mathrm{~d}$ to reach their final destination within the cortical plate (Berry and Rogers, 1965; Hicks and D'Amato, 1968; see also below).

$P 2$. In early postnatal rats, SCIP expression is present in the top half of the cortical plate in a bilaminar pattern (Fig. 8A), whereas hybridization in the intermediate and subventricular zones is weak. Thymidine studies reveal that most of the neurons generated on E16 are now located in roughly the middle 


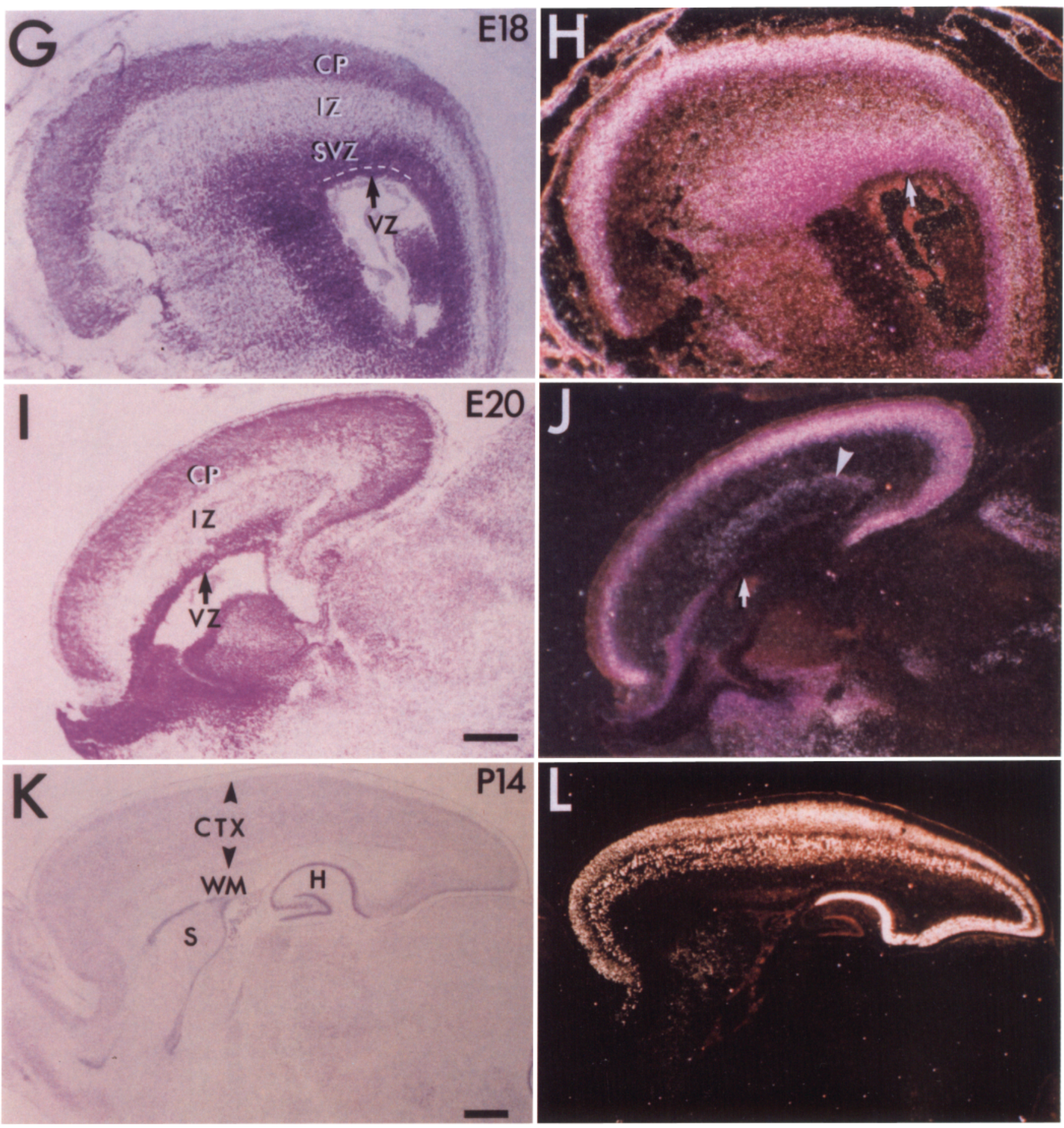

the cerebral cortex, SCIP mRNA is strongly expressed within the intermediate zone and subventricular zone but not within the ventricular zone (arrow). $G$ and $H, \mathrm{E} 18$ : SCIP hybridization is present within the outer cortical plate $(C P)$, the intermediate zone, and subventricular zone, but not the ventricular zone (arrow). $I$ and $J$, E20: within the cortex, the expression of SCIP mRNA is strongest is the cortical plate but is also detectable within a band in the intermediate zone (arrowhead). The ventricular zone (arrow) is devoid of hybridization above background. $K$ and $L$, P14: SCIP expression forms a bilaminar pattern within the cerebral cortex $(C T X)$, but is absent from the white matter $(W M)$. Strong expression is also observed within the CAl region of the hippocampus $(H)$ and more weakly within the striatum $(S)$. Scale bars: $E, 0.5 \mathrm{~mm}$ for $A-H ; I, 0.5 \mathrm{~mm}$ for $I$ and $J ; K, 1 \mathrm{~mm}$ for $K$ and $L$.

of the cortical plate (Fig. $8 B$ ), and many cells in layer 5, which is now distinguishable histologically, are thymidine labeled. The lower zone of intense SCIP hybridization is aligned with cortical layer 5 . There appears to be a region immediately above layer 5 but below the top of the cortical plate in which there is reduced hybridization; this is particularly marked in more lateral and anterior regions of cortex (not shown). Hybridization is intense at the top of the cortical plate (Fig. $8 \mathrm{~A}$ ); Figure $8 \mathrm{C}$ shows that neurons of cortical layer 2/3, tagged with ${ }^{3} \mathrm{H}$-thymidine on E19, have just begun to arrive in this region at $\mathrm{P} 2$, and that many 


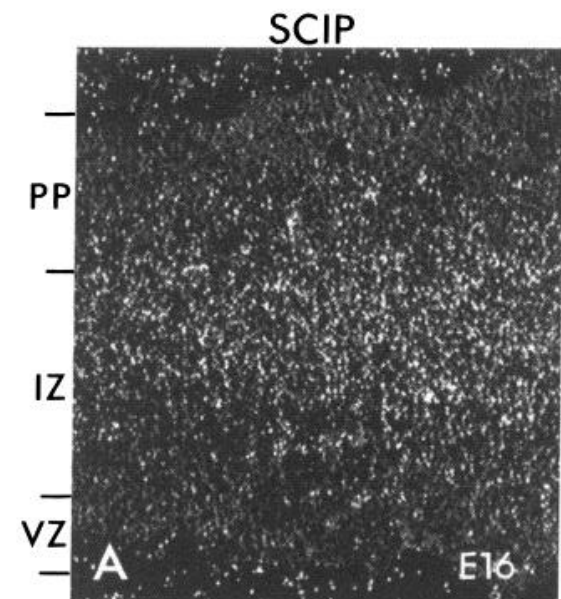

Figure 7. Comparison of the patterns of SCIP hybridization in embryonic rat cerebral wall to the migration of cells labeled with ${ }^{3} \mathrm{H}$-thymidine on E16, most of which are destined to become layer 5 neurons. $A, B$, and $D$, Dark-field views of in situ hybridization for SCIP mRNA. $C$ and $E$, Dark-field views of ${ }^{3} \mathrm{H}$-thymidine-labeled cells at ages comparable to those shown at left in $B$ and $D . V Z$, ventricular zone; $S V Z$, subventricular zone; $I Z$, intermediate zone; $S P$, subplate; $C P$, cortical plate; $M Z$, marginal zone; $P P$, preplate. $A, \mathrm{E} 16$ : SCIP is expressed at low levels in the subventricular and intermediate zones, but is absent from the ventricular zone and cortical plate. $B$ and $C, \mathrm{E} 17$ : strong SCIP hybridization is observed over the subventricular and intermediate zones, but not over the corticar plate or ventricular zone $(B)$. Cells labeled with ${ }^{3} \mathrm{H}$-thymidine on E16 are migrating through the subventricular and intermediate zones on E17, but have not reached the cortical plate $(C)$. Thus, there is a correlation between the positions of migrating deep-layer neurons and the regions of SCIP expression. $D$ and $E$, E20: SCIP expression is visible within the cortical plate, but is absent from the base of the cortical plate where layer 6 neurons are located $(D) .{ }^{3} \mathrm{H}$-Thymidine labeling reveals that the tagged neurons, most of which are destined for cortical layer 5 , have arrived within the cortical plate $(E)$ and are found in a position comparable to the region that shows SCIP hybridization. Scale bar, $100 \mu \mathrm{m}$.
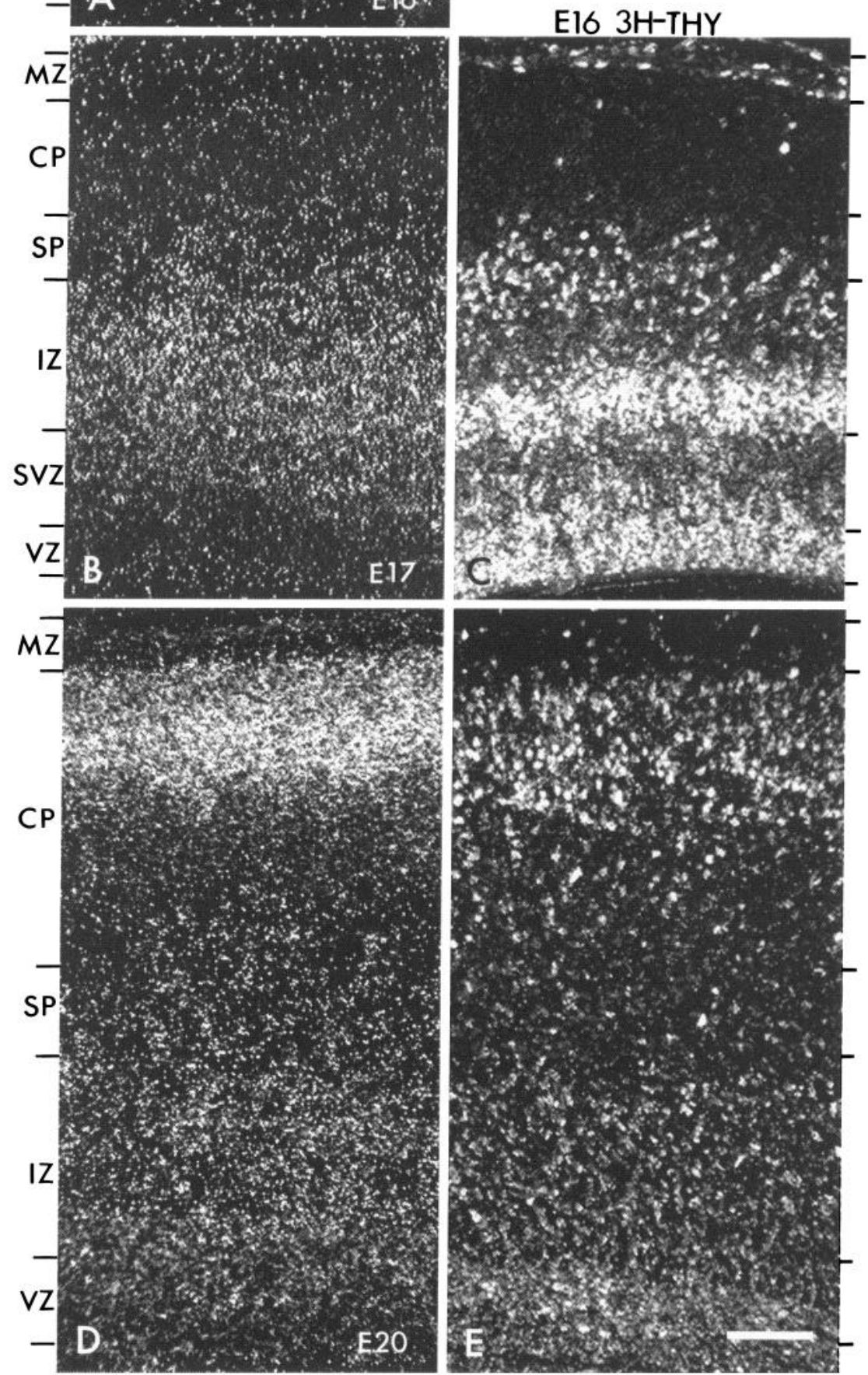
The Journal of Neuroscience, February 1994, 14(2) 481

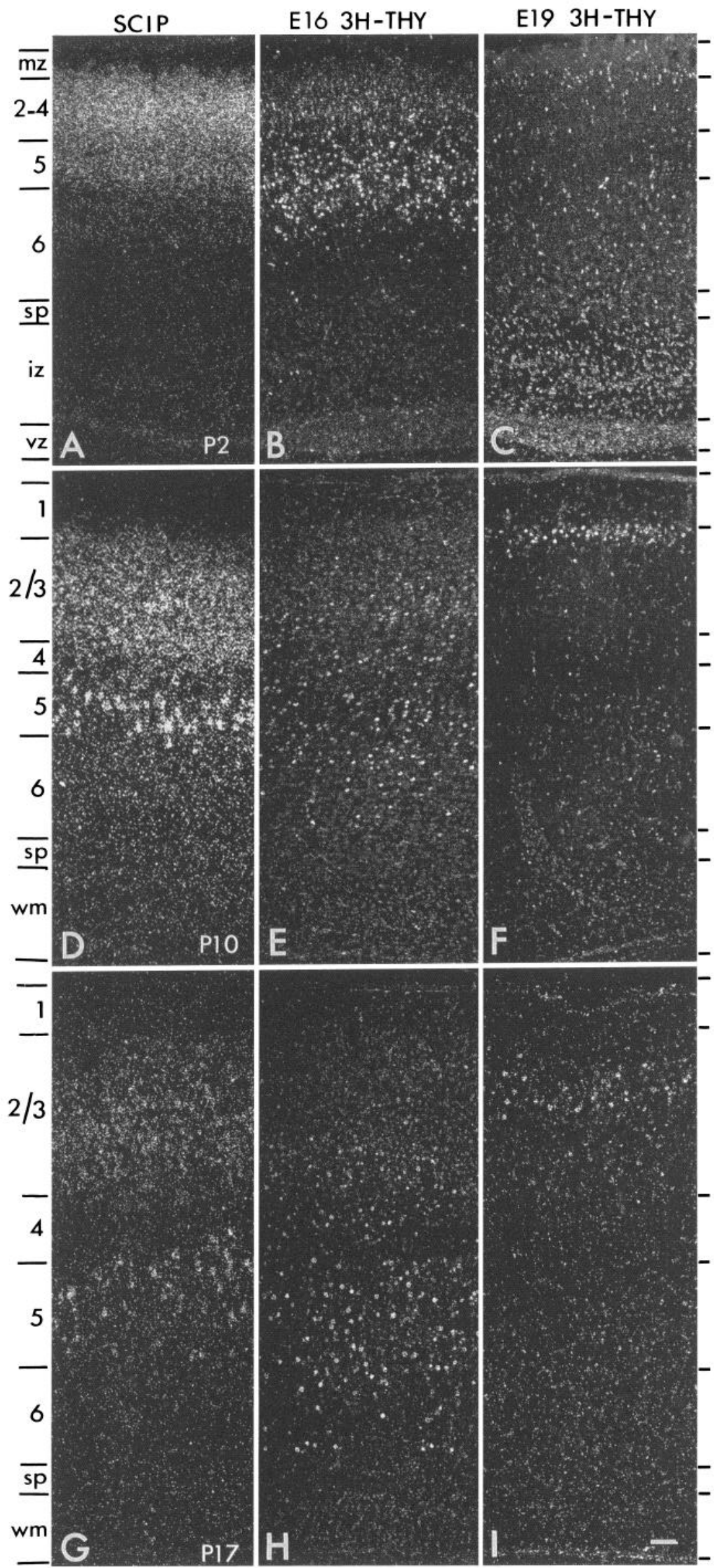

Figure 8. Comparison of the patterns of SCIP hybridization in postnatal rat cerebral wall to the migration of cells labeled with ${ }^{3} \mathrm{H}$-thymidine on E16 (layer 5 neurons) and on E19 (layer 2/3 neurons). $A, D$, and $G$, Dark-field views of patterns of in situ hybridization for SCIP mRNA. $B, E$, and $H$, Dark-field views of cell labeled with ${ }^{3} \mathrm{H}$-thymidine on E16 and observed at ages comparable to those shown at left. $C, F$, and $I$, Dark-field views of cell labeled with ${ }^{3} \mathrm{H}$-thymidine on E19 and observed at ages comparable to those shown at left. $v z$, ventricular zone; $i z$, intermediate zone; $s p$, subplate; $w m$, white matter; $m z$, marginal zone. $A-C$, P2: strong SCIP hybridization is observed over the cortical plate in a weakly bilaminar pattern $(A)$. Note that, in contrast to embryonic animals, SCIP is also expressed within the ventricular zone at this age. Cells labeled with ${ }^{3} \mathrm{H}$-thymidine on E16 are present in their final positions within the deep layers $(B)$, including layer 5 , which is now histologically identifiable. Cells labeled with ${ }^{3} \mathrm{H}$-thymidine on E19, however, are still migrating through the intermediate zone $(C)$, which shows low levels of SCIP hybridization at this age. $D-F, \mathrm{P} 10$ : SCIP expression is strongly bilaminar within the cortical plate $(D)$. Intense hybridization is found over cortical layers $2 /$ 3 and 5 , at roughly comparable levels. ${ }^{3} \mathrm{H}$-thymidine labeling studies reveal that cells labeled on E16 $(E)$ and E19 $(F)$ have reached their final positions within cortical layers 5 and $2 / 3$, respectively. $G-I$, P17: SCIP expression is bilaminar but the levels of expression in layer $2 / 3$ have begun to decrease $(G)$. Cells labeled with ${ }^{3} \mathrm{H}$-thymidine on E16 $(H)$ and E19 $(I)$ are in their final positions within cortical layers 5 and $2 / 3$. Scale bar, $100 \mu \mathrm{m}$. 


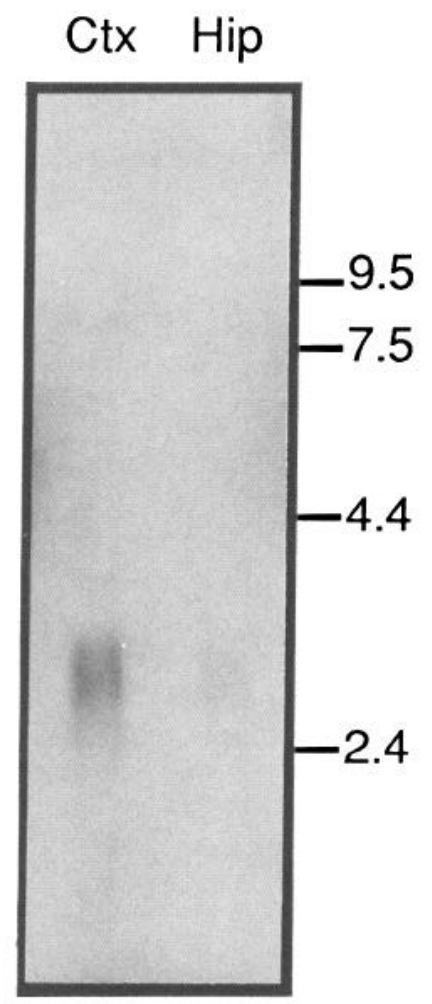

Figure 9. Northern blot analysis of SCIP mRNA expressed in adult rat cerebral cortex $(\mathrm{Ct} x)$ and in hippocampus (Hip). In each of these forebrain regions, the predominant $\mathrm{mRNA}$ transcript has a size of roughly $3.3 \mathrm{~kb}$, comparable to that of the SCIP message expressed by proliferating Schwann cells in the PNS (Monuki et al., 1989). The Ctx lane was loaded with $4.5 \mu \mathrm{g}$ of polyA + mRNA, while the Hip lane was loaded with $1 \mu \mathrm{g}$ of polyA + mRNA.

labeled cells are visible in lower regions, presumably migrating en route to their final destination (Fig. 8C). Interestingly, at P2 SCIP is also expressed within the ventricular zone, even though it was absent from this region at embryonic ages (Fig. 8A).

P6-P14. In the second postnatal week, the pattern of SCIP expression is strongly bilaminar, and the absolute levels of signal appear to have increased (P10, Fig. $8 D$; P14, Fig. $6 K, L$ ). At these ages, the cortical layers are histologically distinct, and it is apparent that the regions of SCIP hybridization correspond to cortical layers 5 and $2 / 3$. Grain counts reveal that cells in these two layers show roughly comparable levels of hybridization (as determined by counting the number of grains per cell). There is no detectable SCIP expression in the ventricular, subventricular, or intermediate zones of the cerebral wall from P6 onward. Comparison of the regions showing SCIP hybridization at P10 shows a good alignment with the positions of thymidinelabeled neurons in cortical layer 5 (E16, Fig. $8 E$ ) and layer $2 / 3$ (E19, Fig. 8F). Upper-layer neurons have completed their migration at this age.

PI7-P21. Decreased levels of SCIP expression are now apparent in the upper cortical plate (Fig. $8 G$ ); grain counts show that by P17, cells in layer 5 express SCIP at roughly twofold greater levels than do cells in the superficial layers. We cannot determine directly whether SCIP is downregulated by layer $2 /$ 3 neurons, or whether SCIP-expressing cells in this layer are culled selectively by cell death. However, the strong and diffuse hybridization patterns observed at earlier stages suggest that differential cell death cannot completely account for the loss of SCIP signal in layer $2 / 3$.

$P 30-P 40$. By the end of the first postnatal month, the adult pattern of SCIP expression has been achieved (not shown). Strong hybridization is confined to neurons in cortical layer 5 , and a weaker signal (roughly sixfold less) is visible in layer $2 / 3$.

\section{Northern blot analysis of SCIP $m R N A$}

A single prominent species of SCIP mRNA is observed in Northern blots of adult cerebral cortex (Fig. 9). The predominant band has a size of roughly $3.3 \mathrm{~kb}$; a transcript of comparable size is also present in the hippocampus. A SCIP transcript of similar size has been observed to be expressed by proliferating Schwann cell precursors in vitro (Monuki et al., 1989).

\section{Discussion}

Here we have shown that the POU homeodomain gene SCIP (also known as Tst-1 and Oct-6) is expressed preferentially in layer 5 pyramidal neurons in the adult rat cerebral cortex, and primarily in those neurons that form subcortical axonal projections. During development, SCIP is also transiently expressed in the upper cortical layers 2 and 3. These findings stand in contrast to those of He et al. (1989), who reported that Tst-1 (identical to SCIP) is expressed in cortical layers 5 and 6 of both developing and adult animals. We have also found that the SCIP gene is initially expressed in cells in the intermediate zone but is absent from the ventricular zone, suggesting that cells that express SCIP begin to do so following their final mitotic division and initiation of migration toward the cortical plate. The timing of onset of SCIP expression within the cerebral wall correlates with the onset of layer 5 neurogenesis. While we could not ascertain whether SCIP is expressed transiently in glial cell progenitors as well as neurons during development, SCIP expression in the adult cortex appears to be entirely neuronal in origin. Thus, we have found a striking difference between peripheral and central patterns of expression of the SCIP gene: in the PNS, SCIP is expressed by proliferating Schwann cell precursors (Monuki et al., 1989, 1990), whereas in the CNS the expression of SCIP correlates primarily with the differentiation of postmitotic neurons.

\section{Developmental regulation of SCIP}

The initial expression of SCIP within the developing cerebral cortex correlates both temporally and spatially with the initiation of migration by the neurons of cortical layer 5 . These neurons are initially generated in substantial numbers on E15 with a peak of neurogenesis on E16 (Fig. 5). Prior to E15, no detectable SCIP hybridization is observed within the developing cerebral wall, with the exception that SCIP is expressed within the preplate of the anteriormost regions of cortex. By E16, a day after the first layer 5 neurons have been generated, SCIP expression appears throughout the rostrocaudal extent of the cortex within the intermediate zone, a region that contains migrating neurons, radial glial fibers, and developing axons. In contrast to a previous report (He et al., 1989), we did not observe SCIP hybridization within the ventricular zone at any time during the period of neurogenesis. Although we have not shown directly that migrating neurons are the cells responsible for the patterns of SCIP hybridization in the intermediate zone, our results are consistent with the interpretation that SCIP is initially expressed at relatively low levels by layer 5 neurons as they 
migrate toward the cortical plate, following their terminal mitotic division.

SCIP expression is observed within the cortical plate at a time and in a pattern that correlates precisely with the arrival of layer 5 neurons in their final positions. The intensity of SCIP hybridization increased over time, concomitant with the continued differentiation of these neurons. At later ages in embryonic development, it was still possible to obscrve levels of SCIP expression above background within the intermediate zone, well after the completion of layer 5 neuronal migration. We believe that these later patterns may reflect the expression of SCIP by migrating layer $2 / 3$ neurons, which are generated between E18 and E20 (Fig. 5; Berry and Rogers, 1965) and migrate into the cortical plate late in embryogenesis and early postnatal life. Comparison of SCIP expression with the pusitions of cells labeled with ${ }^{3} \mathrm{H}$-thymidine on $\mathrm{E} 19$ reveals, for example, that on P2 many presumptive layer $2 / 3$ neurons are still migrating within the intermediate zone, and that SCIP is expressed in this region. Tst-1/SCIP expression was also noted by He et al. (1989) within this zone in neonatal rats.

Cells in the upper layers of the cerebral cortex express SCIP at levels comparable to those in layer 5 neurons for the first 2 postnatal weeks, but this expression is transient. By P17 the levels have begun to decrease, and by $\mathrm{P} 30$ the adult pattern (with roughly sixfold greater expression within layer 5 compared to layer $2 / 3$ ) has been reached. We believe that most if not all of the decrease in SCIP signal within layer $2 / 3$ is due to the downregulation of SCIP expression rather than the selective climination of SCIP-expressing cells. First, at P10 and P14, SCIP expression appears to be ubiquitous within layer $2 / 3$; however, estimates of the extent of cell death within layer $2 / 3$ in the hamster indicate that there is only a small amount of cell death in this layer throughout most regions of cortex (Finlay, 1992). Second, very low levels of SCIP hybridization are observed in adult upper-layer neurons, showing that at least some SCIP-expressing neurons can survive the period of cell death. Thus, cell death cannot account completely for the loss of SCIP expression in the upper layers. We do not know either the cause or the functional significance of this downregulation.

\section{Neuronal versus glial expression of SCIP in developing cortex}

Previous studies have revealed that SCIP is expressed at high levels in the PNS by proliferating Schwann cell progenitors (Monuki et al., 1989, 1990), and that the targets of transcriptional regulation may include myelin genes such as $\mathbf{P}_{0}$ (Monuki et al., 1990, 1993). Thus, it has been hypothesized that the function of SCIP in the PNS is to maintain the proliferative state and repress the differentiation of Schwann cells (Monuki et al., 1989, 1990). We were surprised to find that in the CNS, SCIP is expressed at times and in places that correlate with the differentiation of neurons. Indeed, SCIP expression was not detectable in the cerebral ventricular zone, the primary region in which neuronal precursor cells proliferate, but was instead observed first in the subventricular and intermediate zones, regions occupied by migrating postmitotic neurons. Thus, in contrast to its putative role in maintaining the proliferative state in the PNS, SCIP expression in CNS neurons correlated temporally and spatially with the cessation of cell division and the initiation of migration and differentiation.

Interestingly, however, we observed faint SCIP expression in the ventricular zone of $\mathrm{P} 2$ animals at times after the period of neurogenesis has ended, but during the time of genesis of glial cells (Richardson et al., 1990). SCIP mRNA is expressed at low levels in vitro by proliferating O2A progenitor cells (Collarini et al., 1992), which are capable of generating both oligodendrocytes and astroglia, and are present in the developing cerebral cortex (reviewed in Richardson et al., 1990). This expression is downregulated when $\mathrm{O} 2 \mathrm{~A}$ cells are stimulated to differentiate into either oligodendrocytes or astrocytes. Thus, our finding that SCIP hybridization is absent from mature glial cells within the cortex and white matter is consistent with previous studies indicating that the SCIP is expressed by proliferating glial cell precursors, but not by differentiated glia, in both the CNS and PNS (Monuki et al., 1989, 1990; Collarini et al., 1992). The interesting possibility is raised that SCIP expression we have observed in the postnatal ventricular zone may be associated with the onset of gliogenesis. Studies in rat have suggested, however, that $\mathrm{O} 2 \mathrm{~A}$ progenitor cells (marked with an antibody to the ganglioside GD3, or by in situ hybridization for the platelet-derived growth factor- $\alpha$ receptor) are first produced within the subventricular zone in small numbers between E 6 and E1 8 in the rat cortex, and subsequently move into the intermediate zone and possibly the cortical plate at around birth and during early postnatal periods (LeVine and Goldman, 1988; Hardy and Reynolds, 1991; Pringle et al., 1992). These results are consistent with the possibility that at least some of the cxpression of SCIP mRNA that we observed in the subventricular and intermediate zones at pre- and postnatal ages may have been associated with the proliferation of glial cell progenitors (but does not account for the expression of SCIP in the P2 ventricular zone). We were unable to determine directly whether the expression of SCIP observed at prenatal ages is entirely neuronal in origin, or whether at least some of this expression may have been associated with the proliferation of $\mathrm{O} 2 \mathrm{~A}$ progenitor cells in the subventricular and intermediate zones.

\section{Axonal projections of SCIP-expressing neurons}

Within most regions of the adult cerebral cortex, SCIP expression was confined almost entirely to those neurons in layer 5 that form subcortical axonal projections. When layer 5 neurons projecting to the midbrain or across the corpus callosum were retrogradely labeled with Fluorogold and then processed for in situ hybridization, roughly two-thirds of the subcortical projection neurons also expressed SCIP, whereas only about $5 \%$ of callosally projecting neurons did so. This is particularly interesting since it has been shown that these two classes of projection neurons are distinct throughout development: subcortical projection neurons appear never to extend axons to cortical targets, and vicc vorsa (O'Leary and Stanficld, 1985). Thus, the expression of SCIP in one subtype of layer 5 neuron may play a role in determining the difference between these two cell types. It seems unlikely, however, that SCIP expression alone is a sufficient determinant of the subcortical projection phenotype. First, we do not know whether the expression of SCIP within layer 5 during development is confined to subcortical projection neurons; it remains possible that this gene is transiently expressed in cortical projection cells as well. Second, SCIP is transiently expressed in the upper layers, in neurons that presumably form cortical projections. Finally, in more rostral (frontal) regions of cortex, the correlation between SCIP expression and projection pattern is less strong since in frontal cortex a much larger fraction (about $33 \%$ ) of neurons with callosal axons also express SCIP. While these results do not rule out a possible role for SCIP in the determination of axonal phenotype in the cerebral 
cortex, they do suggest that SCIP cannot serve as the sole determinant of a neuron's axonal projection pattern.

\section{SCIP and the laminar patterning of cerebral cortex}

Several sets of experiments have suggested that, in contrast to the formation of cortical areas, laminar differences among cortical neurons are determined early in development. Studies in which presumptive deep-layer neurons are transplanted into older host brains have revealed that the laminar identities of cortical neurons are determined during their final cell cycle, just prior to mitosis (McConnell, 1988; McConnell and Kaznowski, 1991). These experiments have also shown that, once committed, a migrating cortical neuron can "home" to its correct layer, suggesting that these cells can actively recognize their appropriate laminar address (McConnell, 1988; McConnell and Kaznowski, 1991). Studies of the normal development of axon collaterals from upper-layer cortical neurons have shown that local axons form in an appropriate, layer-specific manner from the outset during development (Katz, 1991). Finally, in cocultures that consist of small pieces of cortex and a variety of possible targets, neurons extend axons toward targets in a manner that preserves and reflects their normal laminar identities (Bolz et al., 1990; Yamamoto et al., 1992). Collectively, these findings imply that there must be molecular distinctions between the layers that are present at early times in development, at least during the periods of neurogenesis, migration, and axon outgrowth.

The finding that SCIP is expressed in lamina-specific patterns in both the adult and developing cortex raises the possibility that SCIP plays some role in creating laminar differences among cortical neurons. This is a particularly interesting possibility since POU homeodomain genes have been implicated in the regulation of cell fates in C. elegans (unc-86; Finney et al., 1988) and in the mammalian pituitary (Pit-1: Ingraham et al., 1988; Li et al., 1990; Pfaffle et al., 1992). Expression of SCIP at high levels in adult cortex is confined to neurons within cortical layer 5; however, SCIP is transiently expressed at equally high levels during development in layer $2 / 3$ (a single layer, despite its name, as defined by the projection patterns of its constituent neurons). This implies that SCIP expression alone is unlikely to be sufficient to specify an individual laminar phenotype, although it is possible that SCIP could act combinatorially with other, as yet unknown transcription factors. The pattern of expression is intriguingly reminiscent of the expression of Hox genes within the rhombomeres of the hindbrain. In the hindbrain, the anterior limits of gene expression correspond to rhombomere boundaries and moreover seem to observe a two segment rule. Specific members of the Hox 2 cluster are expressed from caudal areas to the posterior boundaries of rhombomeres $8,6,4$, and 2 , thus demarcating every other segment, and Krox-20 is expressed selectively in rhombomeres 3 and 5 (Wilkinson et al., 1989). Furthermore, pairs of segments contribute to common cranial nerves (e.g., rhombomeres 2 and 3 contribute to the $V$ th cranial nerve, and 4 and 5 form the VIIth nerve) (Lumsden, 1990). In the developing cerebral cortex, the expression of SCIP in layer $2 / 3$ and in layer 5 forms a pattern in which every other layer is skipped over: layers 1,4 , and 6 do not express SCIP above background. Interestingly, the neurons of layers $2 / 3$ and 5 are interconnected by local axonal circuits: layer $2 / 3$ neurons form axon collaterals within layer 5 , and layer 5 cells send reciprocal innervation back up to layer 2/3 (Gilbert, 1983; Martin and Whitteridge, 1984; Gilbert and Wiesel, 1985).
The onset of detectable SCIP expression is delayed relative to the onset of laminar commitment, as revealed by transplantation experiments. The latter experiments have shown that presumptive deep-layer neurons make a commitment to their normal laminar fates just prior to their final mitotic division, in roughly G2 of the cell cycle (McConnell and Kaznowski, 1991). SCIP hybridization is first observed, however, in the intermediate zone, the region where postmitotic neurons are migrating toward the cortical plate. Thus, it seems likely that rather than being involved in the commitment event itself, SCIP expression is correlated with the onset of cell-specific differentiation and migration, although it is possible that SCIP expression is initiated earlier but remains at levels too low to be detected by in situ hybridization. Whether SCIP is involved directly in the generation of laminar patterning remains to be tested, by either gene knockout or overexpression experiments.

\section{References}

Angevine JR Jr, Sidman RL (1961) Autoradiographic study of cell migration during histogenesis of cerebral cortex in the mouse. Nature 192:766-768.

Bayer SA, Altman J (1990) Development of layer I and the subplate in the rat neocortex. Exp Neurol 107:48-62.

Berry M, Rogers AM (1965) The migration of neuroblasts in the developing cerebral cortex. J Anat 99:691-709.

Bodner M, Castrillo J-L, Theill LE, Deerinck T, Ellisman M, Karin M (1988) The pituitary-specific transcription factor GHF-1 is a homeobox-containing protein. Cell 55:505-518.

Bolz J, Novak N, Götz M, Bonhoeffer T (1990) Formation of targetspecific neuronal projections in organotypic slice cultures from rat visual cortex. Nature 346:359-362.

Brodmann K (1909) Lokalisationslehre der Groshirnrinde in ihren Principen dargestellt aus Grund des Zellen baue. Leipzig: Barth.

Collarini EJ, Kuhn R, Marshall CJ, Monuki ES, Lemke G, Richardson WD (1992) Down-regulation of the POU transcription factor SCIP is an early event in oligodendrocyte differentiation in vitro. Development 116:193-200.

Cunningham ETJ, Simmons DM, Swanson LW, Sawchenko PE (1991) Enkephalin immunoreactivity and messenger RNA in a discrete projection from the nucleus of the solitary tract to the nucleus ambiguus in the rat. J Comp Neurol 307:1-16.

Finlay BL (1992) Cell death and the creation of regional differences in neuronal numbers. J Neurobiol 23:1159-1171.

Finney M, Ruvkun G, Horvitz HR (1988) The $C$. elegans cell lineage and differentiation gene $u n c-86$ encodes a protein with a homeodomain and extended similarity to transcription factors. Cell 55:757769.

Fishell G, Mason CA, Hatten ME (1993) Dispersion of neural progenitors within the germinal zones of the forebrain. Nature 362:636638.

Fraser S, Keynes R, Lumsden A (1990) Segmentation in the chick embryo hindbrain is defined by cell lineage restrictions. Nature 344 : $431-435$.

Gilbert CD (1977) Laminar differences in receptive field properties of cells in cat primary visual cortex. J Physiol (Lond) 268:391-421.

Gilbert CD (1983) Microcircuitry of the visual cortex. Annu Rev Neurosci 6:217-247.

Gilbert CD, Kelly JP (1975) The projections of cells in different layers of the cat's visual cortex. J Comp Neurol 163:81-106.

Gilbert CD, Wiesel TN (1985) Intrinsic connectivity and receptive field properties in visual cortex. Vision Res 25:365-374.

Guthrie S, Lumsden A (1991) Formation and regeneration of rhombomere boundaries in the developing chick hindbrain. Development 112:221-229.

Guthrie S, Lumsden A (1992) Motor neuron pathfinding following rhombomere reversals in the chick embryo hindbrain. Development 114:663-673.

Hardy R, Reynolds R (1991) Proliferation and differentiation potential of rat forebrain oligodendroglial progenitors both in vitro and in vivo. Development 111:1061-1080.

He X, Treacy MN, Simmons DM, Ingraham HA, Swanson LW, Rosenfeld MG (1989) Expression of a large family of POU-domain 
regulatory genes in mammalian brain development. Nature 340:3542.

He X, Gerrero R, Simmons DM, Park RE, Lin CR, Swanson LW, Rosenfeld MG (1991) Tst-1, a member of the POU domain gene family, binds the promoter of the gene encoding the cell surface adhesion molecule $\mathbf{P}_{0}$. Mol Cell Biol 11:1739-1744.

Herr W, Sturm RA, Clerc RG, Corcoran LM, Baltimore D, Sharp PA Ingraham HA, Rosenfeld MG, Finney M, Ruvkun G, Horvitz HR (1988) The POI domain: a large conserved region in the mammalian pit-1, oct-1, oct-2 and Caenorhabditis elegans unc-86 gene products. Genes Dev 2:1513-1516.

Hicks SP, D'Amato CJ (1968) Cell migrations to the isocortex in the rat. Anat Rec 160:619-634.

Ingraham HA, Chen R, Mangalam HJ, Elsholtz HP, Flynn SE, Lin CR, Simmons DR, Swanson L, Rosenfeld MG (1988) A tissue-specific transcription factor containing a homeodomain specifies a pituitary phenotype. Cell 55:519-529.

Katz LC (1991) Specificity in the development of vertical connections in cat striate cortex. Eur J Neurosci 3:1-9.

Koester SE, O'Leary DD (1992) Functional classes of cortical projection neurons develop dendritic distinctions by class-specific sculpting of an early common pattern. J Neurosci 12:1382-1393.

Kreig W (1946) Connections of the cerebral cortex. I. The albino rat. A. Topography of the cortical areas. J Comp Neurol 84:22I-275.

LeVay S, McConnell SK, Luskin MB (1987) Functional organization of primary visual cortex in the mink (Mustela vison), and a comparison with the cat. J Comp Neurol 257:422-441.

LeVine SM, Goldman JE (1988) Embryonic divergence of oligodendrocyte and astrocyte lineages in developing rat cerebrum. J Neurosci 8:3992-4006.

Li S, Crenshaw EBI, Rawson EJ, Simmons DM, Swanson LW, Rosenfeld MG (1990) Dwarf locus mutants lacking three pituitary cell types result from mutations in the POU-domain gene pit-1. Nature 347:528-533.

Lumsden A (1990) The cellular basis of segmentation in the developing hindbrain. Trends Neurosci 13:329-335.

Lumsden A. Keynes R (1989) Segmental patterns of neuronal development in the chick hindbrain. Nature 337:424-428.

Lund JS, Lund RD, Hendrickson AE, Bunt AH, Fuchs AF (1975) The origin of efferent pathways from the primary visual cortex, area 17, of the macaque monkey as shown by retrograde transport of horseradish peroxidase. J Comp Neurol 164:287-304.

Luskin MB, Shatz CJ (1985a) Neurogencsis of the cat's primary visual cortex. J Comp Neurol 242:611-631.

Luskin MB, Shatz CJ (1985b) Studies of the earliest generated cells of the cat's visual cortex: cogeneration of subplate and marginal zones. J Neurosci 5:1062-1075.

Martin KAC, Whitteridge D (1984) Form, function and intracortical projections of spiny neurones in the striate visual cortex of the cat. $J$ Physiol (Lond) 353:463-504.

McConnell SK (1988) Fates of visual cortical neurons in the ferret after isochronic and heterochronic transplantation. J Neurosci 8:945974.

McConnell SK (1992) The genesis of neuronal diversity during development of cerebral cortex. Semin Neurosci 4:347-356.

McConnell SK, Kaznowski CE (1991) Cell cycle dependence of laminar determination in developing cercbral cortcx. Science 254:282285.

McConnell SK, LeVay S (1986) Anatomical organization of the visual system of the mink (Mustela vison). J Comp Neurol 250:109-132.

Miller MW (1985) Cogeneration of retrogradely labeled corticocortical projection and GABA-immunoreactive local circuit neurons in cerebral cortex. Dev Brain Res 23:187-192.

Monuki ES, Weinmaster G, Kuhn R, Lemke G (1989) SCIP: a glial POU domain gene regulated by cyclic AMP. Neuron 3:783-793.

Monuki ES, Kuhn R, Weinmaster G, Trapp BD, Lemke G (1990) Expression and activity of the POU transcription factor SCIP. Science 249:1300-1303

Monuki ES, Kuhn R, Lemke G (1993) Repression of the myelin $P_{0}$ gene by the POU transcription factor SCIP. Mech Dev 42:15-32.

O'Leary DDM (1989) Do cortical areas emerge from a protocortex? Trends Neurosci 12:400-406.

O'Leary DDM, Stanfield BB (1985) Occipital cortical neurons with transient pyramidal axons extend and maintain collaterals to subcortical but not intracortical targets. Brain Res 336:326-333.
O'Leary DDM, Stanfield BB (1989) Selective elimination of axons extended by developing cortical neurons is dependent on regional locale: experiments utilizing fetal cortical transplants. J Neurosci 9:2230-2246.

O'Rourke NA, Dailey ME, Smith SJ, McConnell SK (1992) Diverse migratory pathways in the developing cerebral cortex. Science 258 : 299-302.

Paxinos G, Watson C (1986) The rat brain in stereotaxic coordinates. Orlando, FL: Academic.

Pfaffle RW, DiMattia GE, Parks JS, Brown MR, Wit JM, Jansen M, Van der Nat H, Van den Brande JL, Rosenfeld MG, Ingraham HA (1992) Mutation of the POU-specific domain of Pit-1 and hypopituitarism without pituitary hypoplasia. Science 257:1118-1121.

Porteus MH, Bulfone A, Ciaranello RD, Rubenstein JL (1991) Isolation and characterization of a novel cDNA clone encoding a homeodomain that is developmentally regulated in the ventral forebrain. Neuron 7:221-229.

Price M, Lemaistre M, Pischetola M, DiLauro R, Duboule D (1991) A mouse gene related to Distal-less shows a restricted expression in the developing forebrain. Nature 351:748-751.

Price M, Lazzaro D, Pohl T, Mattei MG, Ruther U, Olivo JC, Duboule D, DiLauro R (1992) Regional expression of the homeobox gene $\mathrm{Nkx}-2.2$ in the developing mammalian forebrain. Neuron 8:241-255.

Pringle NP, Mudhar HS, Collarini EJ, Richardson WD (1992) PDGF receptors in the rat CNS: during late neurogenesis, PDGF alphareceptor expression appears to be restricted to glial cells of the oligodendrocyte lineage. Development 115:535-551.

Rakic $P$ (1974) Neurons in the rhesus monkey visual cortex: systematic relationship between time of origin and eventual disposition. Science 183:425-427.

Richardson WD, Raff M, Noble M (1990) The oligodendrocyte-type-2 astrocyte lineage. Semin Neurosci $2: 445-454$.

Rosenfeld MG (1991) POU-domain transcription factors: pou-er-ful developmental regulators. Genes Dev 5:897-907.

Sambrook J, Fritsch EF, Maniatis T (1989) Molecular cloning: a laboratory manual. Cold Spring Harbor, NY: Cold Spring Harbor Laboratory.

Schlagger BL, O'Leary DDM (1991) Potential of visual cortex to develop an array of functional units unique to somatosensory cortex. Science 252:1556-1560.

Schöler HR (1991) Octamania: the POU factors in murine development. Trends Genet 7:323-329.

Shatz C (1992) Dividing up the ncocortcx. Science 258:237-238.

Simeone A, Acampora D, Gulisano M, Stornaiuolo A, Boncinelli E (1992a) Nested expression domains of four homeobox genes in developing rostral brain. Nature 358:687-690.

Simeone A, Gulisano M, Acampora D, Stornaiuolo A, Rambaldi M, Boncinelli E (1992b) Two vertebrate homeobox genes related to the Drosophila empty spiracles gene are expressed in the embryonic cerebral cortex. EMBO J 11:2541-2550.

Simmons DM, Arriza JL, Swanson LW (1989) A complete protocol for in situ hybridization of messenger RNAs in brain and other tissues with radiolabeled single-stranded RNA probes. J Histotech 12:169181 .

Stanfield BB, O'Leary DDM (1985) Fetal occipital cortical neurones transplanted to the rostral cortex can extend and maintain a pyramidal tract axon. Nature 313:135-137.

Suzuki N, Rohdewohld H, Neuman T, Gruss P, Schöler HR (1990) Oct-6: a POU transcription factor expressed in embryonal stem cells and in the developing brain. EMBO J 9:3723-3732.

Symonds LL, Rosenquist AC (1984) Laminar origins of visual corticocortical connections in the cat. J Comp Neurol 229:39-47.

Walsh C, Cepko CL (1992) Widespread dispersion of neuronal clones across functional regions of the cerebral cortex. Science 255:434-440.

Wilkinson DG, Krumlauf R (1990) Molecular approaches to the segmentation of the hindbrain. Trends Neurosci 13:335-339.

Wilkinson DG, Bhatt S, Cook M, Boncinelli E, Krumlauf R (1989) Segmental expression of Hox-2 homeobox-containing genes in the developing mouse hindbrain. Nature 341:405-409.

Yamamoto N, Yamada K, Kurotani T, Toyama K (1992) Laminar specificity of extrinsic cortical connections studied in coculture preparations. Neuron 9:217-228. 